\title{
A cointegrating stock trading strategy: application to listed tanker shipping companies
}

\author{
Nektarios A. Michail ${ }^{1}$ and Konstantinos D. Melas ${ }^{2 *}$ D
}

\author{
* Correspondence: kmelas@uclan.ac. \\ ${ }^{2}$ School of Business and \\ Management, University of Central \\ Lancashire, Cyprus Campus, 12 - 14 \\ University Avenue Pyla, 7080 \\ Larnaka, Cyprus \\ Full list of author information is \\ available at the end of the article
}

\begin{abstract}
In the current paper, we propose a strategy to trade a portfolio of listed shipping companies in the US market. In particular, we estimate a co-integrating relationship between the weekly stock market returns of a portfolio of tanker shipping companies and the Baltic Tanker Index, exploiting the close relationship between freight rates and the stock market performance of shipping companies. Our results suggest that a trading strategy on the basis of a co-integrating relationship and a simple moving average rule outperforms, by approximately 50\%, a standard buy-and-hold strategy in various investment horizons, often by a very wide margin. Given the latter, the results allow us to enhance the current literature on shipping finance by providing evidence of how simple investment strategies can benefit both retail and institutional investors who do not have direct exposure or experience in the shipping industry by allowing them to include shipping stocks in their portfolios.
\end{abstract}

Keywords: Trading, Cointegration, Tanker, Stock market

The shipping industry has not been open for a wider circle of investors since its inception (Harlafti and Papakonstantinou 2013). Ties within the industry have been close and family relationships have been, most often than not, predominant (Harlaftis and Theotokas 2007). Nevertheless, the increase in vessel prices since the 1970s has brought up the question of whether shipping companies should use external lending financing or float in the markets. Nonetheless, it was not until the mid-2000s that an increasing number of shipping enterprises decided to relinquish information of their modus operandi and enlist in the world stock markets (Merikas et al. 2009).

The increased number of companies in the market provided investors with an alternative way to invest in the shipping industry. Interested parties no longer need to acquire actual assets (vessels) but only hold stocks of shipping companies. Even in this case, however, little is currently known regarding the performance of the shipping companies in the stock market. The existing literature just provides information regarding IPOs (Merikas et al. 2009) and M\&As (Alexandrou et al. 2014) in the industry. Nonetheless, there exists no study, at least to our knowledge, which employs a trading strategy based solely on shipping stock companies.

In the current paper, we build on the literature's premise that freight rates are the predominant factor which affects the companies' performance (see also next Section) and propose a trading strategy for a portfolio of tanker shipping companies that are

(c) The Author(s). 2019 Open Access This article is distributed under the terms of the Creative Commons Attribution 4.0 International License (http://creativecommons.org/licenses/by/4.0/), which permits unrestricted use, distribution, and reproduction in any medium, provided you give appropriate credit to the original author(s) and the source, provide a link to the Creative Commons license, and indicate if changes were made. 
listed in the US stock markets. As expected, we find that these companies exhibit a long-run common path with the Baltic Tanker Index. Given this relationship, we propose a long-short trading strategy on the basis of a cointegration model and a simple moving average rule, which appears to outperform the classic buy-and-hold approach across various investment horizons, often by a wide margin. We have employed the buy-and-hold approach as a benchmark of our strategy, since it tends to be denoted to investors that are not actively trading in the stock markets (Shilling 1992). Thus, we propose that the specific active trading technique, that we propose, can give higher returns when compared to a passive investment strategy.

The remainder of the paper is organized as follows: the next section provides a review of the existing literature on the shipping companies' stock prices, their unique characteristics and the (non-stock market) trading strategies that have been introduced by other researchers. Section 3 presents the methodology and the data we have used, Section 4 offers the results and the last Section provides a general overview along with the conclusions reached by this paper.

\section{Literature review}

The majority of the shipping-related literature has, until now, focused on the management perspective of shipping companies; either for firms which were or are still held private, or for those which are publicly listed in stock markets. Under this prism, performance of the companies has been vastly researched (inter alia, Panayides et al. 2011; Merika et al. 2015; Lambertides and Louca 2008). While performance, and more precisely financial performance, is not always a direct paragon of stock market returns, it nevertheless surely serves as a good proxy (DeBondt and Thaler 1985).

On a more stock price-oriented stream of literature, shipping stocks have been found to exhibit some unique characteristics when compared to stocks from other economic sectors, primarily due to the globalized nature of the sector's operations. More precisely, previous researchers have found that market betas are of little importance for shipping stocks (Tezuka et al. 2012), leading to the conclusion that country-specific systematic risk is not particularly important for investors in shipping companies. The low importance of country-specific factors in the stock performance of shipping companies is even more evident when foreign exchange rates are considered. Given that US dollars are the predominant currency that it is used by shipping companies, the majority actively uses currency hedging techniques that ultimately leave companies indifferent from fluctuations in the currency markets (El-Masry et al. 2010).

On the other hand, variables that are more closely related with world economic outlook, like the G-7 industrial production (Papapostolou et al. 2014), changes in oil prices (Drobetz et al. 2010) and economic crises (Papapostolou et al. 2016), play a more important role in assessing the risk outlook of the shipping companies and subsequently their stock market performance.

Taking the above into consideration leaves investors in shipping companies in a conundrum: which are the factors that one can rely upon when investment strategies are drawn? Perhaps unsurprisingly, Syriopoulos and Roumpis (2009) show that the most important factor that can explain and predict shipping stock performance is freight rates. This finding makes intuitive sense, given that, from a financial accounting 
perspective, freight rates will ultimately determine the amount of income received (sales) by any given shipping company.

Various researchers have tried to explore additional factors which are important in assessing stock price performance of shipping firms. Grammenos and Marcoulis (1996), in their seminal work, provide evidence that financial leverage and the average age of the fleet have an explanatory power over the shipping stock returns. Additionally, Kavussanos and Marcoulis (2000a, 2000b) provide evidence on the macro-economic factors that are affecting shipping stock returns. In their studies they record that shipping stock returns have a positive relationship with oil prices and a negative one with industrial production. Drobetz et al. (2010) further strengthen these findings as they demonstrate the strong relationship of oil prices and industrial production for the period 1997 to 2007. Finally, Grammenos and Arkoulis (2002) show that oil prices and laid up tonnage are inversely related to shipping stocks, whereas the exchange rate exhibits a positive relationship.

On a broader level, though, the financialization of the wider spectrum of commodities has raised the interest of the research community on the linkages that exist between commodities and the stock markets (Basak and Pavlova 2016). While oil remains one of the main factors affecting stock price volatility (Sadorsky 1999), other commodities are also exhibiting a high correlation with the stock market. More precisely, Creti et al. (2013), show that during times of economic stability the correlation between the major commodities and the S\&P500 is evident. Furthermore, the authors show that oil, coffee and cocoa are acting as speculative alternative assets as their correlation with the markets is strengthened during bullish periods and diminished during bearish ones. Finally, gold exhibits a safe haven character since it exhibits a negative correlation over time with the stock markets.

In the current paper, we exploit the stream of literature that embraces econometric techniques in portfolio-oriented investment strategies so as to produce above-average returns from trading in shipping companies. We derive our technique from the seminal work of Alexander (1999), who uses cointegration as a trading technique so as to hedge three different stock portfolios from the volatility that exists in the global financial markets. Even before their stock market application, hedging techniques based on the cointegration approach had also been used in the futures (Ghosh 1991) and the currency markets (Kroner and Sultan 1993).

However, cointegration has not been used for stocks in the shipping sector. The most related studies to this one are Alizadeh and Nomikos (2006), who use a cointegration approach to time buying and selling of ships in the tanker market, and Andriosopoulos et al. (2013) who use h stochastic optimization (heuristic) methods to reduce shippingrelated investment risks and achieve the equivalent performance as the shipping indices and the shipping stocks.

However, this paper differs significantly from the above two studies. In particular, the Alizadeh and Nomikos (2006) approach is not suitable for retail investors, or even the majority of institutional investors who do not possess knowledge in the shipping sector. Furthermore, the Andriosopoulos et al. (2013) approach focuses on reducing risk instead of increasing performance and uses a much more complicated strategy than the one employed here.

In this paper, we follow the suggestions of the previous literature that the stock performance of a portfolio of tanker shipping companies is only affected by freight rates 
and thus exclude any factors that are either irrelevant or difficult to include to a model. To make the model suitable for the portfolio of shipping companies we seek to trade, we use the Baltic Tanker Index as an indicator for market conditions. ${ }^{1}$ We expect that, ceteris paribus, our portfolio's returns and the Baltic Tanker Index will move together in the long-run and share a cointegrating relationship. Any deviations from the cointegrating equation will trigger our trading strategy which is discussed in the next section.

\section{Methodology and data}

The general Vector Error Correction specification, following Johansen and Juselius (1990) is defined as:

$$
\begin{aligned}
& \Delta B T_{t}=a_{1,0}+\sum_{i=1}^{p} \beta_{1, i} \Delta B T_{t-i}+\sum_{i=1}^{p} y_{1, i} \Delta P_{t-i}+\delta\left(B T_{t-1}-\theta_{1} P_{t-1}-\theta_{0}\right)+\varepsilon_{1, t} \\
& \Delta P_{t}=a_{2,0}+\sum_{i=1}^{p} \beta_{2, i} \Delta P_{t-i}+\sum_{i=1}^{p} y_{2, i} \Delta B T_{t-i}+\delta\left(B T_{t-1}-\theta_{1} P_{t-1}-\theta_{0}\right)+\varepsilon_{2, t}
\end{aligned}
$$

where $B T_{t}$ is the natural logarithm of the Baltic Tanker Index, which is comprised as the average clean and dirty tanker index $P_{t}$ is the natural logarithm of an equal-weight portfolio comprising of shipping companies participating in the tanker transportation market, and $\Delta$ is the first difference operator. $\beta_{i, i}$ and $\gamma_{i, i}$ refer to the own and other variable coefficient values in the estimations, while $\varepsilon_{i, t}$ refer to the error processes in each equation.

The long-run relationship between the two variables is found within the brackets of eqs. (1) and (2) with $\delta$ determining the speed of adjustment to the long-run equilibrium. A theoretical generalisation as to why there should be a relationship between freight rates and stock market returns can be justified in a similar manner as in Alizadeh and Nomikos (2006, p.122). ${ }^{2}$

All data were obtained from Clarksons' Intelligence Network and Thompson-Reuters Eikon. Initially, we have collected all the shipping companies that are listed in the US stock markets and their respective SIC code that concerns sea transportation. Accordingly, we have gone through the financial statements of the companies and included in our sample only those whose fleet consists of tankers more than $66 \%{ }^{3}$ Thus, we have been able to collect the respective data for 4 companies which abide by our previouslymentioned criteria, along with a timespan sufficient to provide robust empirical results. The four companies are: DHT Holding, Teekay, Tsakos Energy Nav, and Capital Product Partners. After collecting the data for the prices of stocks, we are calculating their weekly

\footnotetext{
${ }^{1}$ Given that information regarding the split between Clean and Dirty Tanker voyages is impossible to obtain, we have averaged the values of the Clean Index and the Dirty Index. This makes no qualitative and very small quantitative difference to the results, as the correlation between the two indices stands at 0.87 .

${ }^{2}$ The long run, as per Johansen and Juselius (1990), refers to the equilibrium relationship between the variables, i.e. one that would be reached in the absence of any external shocks. Similarly, short run refers to the fluctuations which take place and allow for deviations from the equilibrium value. As such, the terms "long run" and "short run" do not refer to any predetermined time period - it is simply how econometricians refer to these relationships, derived from theoretical models which define the long run as a period with no shocks.

${ }^{3}$ The financial statements examined are for the year 2017. However, it is highly unlikely for a listed company to massively change their fleet outlook from one specific ship type to another in a short period of time, given that if the owners of the company want to start a new line of business, a new enterprise is likely to be incorporated.
} 
Table 1 Unit root tests

\begin{tabular}{llc}
\hline Variable & ADF & $P P$ \\
\hline Levels & & \\
$\ln B T_{t}$ & -1.14 & -0.95 \\
$\ln P_{t}$ & -0.67 & -0.66 \\
First Differences: & $-14.39^{* * *}$ & $-15.15^{* * *}$ \\
$\Delta \ln B T_{t}$ & $-19.73^{* * *}$ & $-19.75^{* * *}$ \\
$\Delta \ln P_{t}$ &
\end{tabular}

average prices, so as to match the latter with the average prices of the Baltic Tanker Index. The data span from the 12th of April 2006 to the 10th of February, 2017, at a weekly frequency with a total of 566 observations. ${ }^{4}$

To empirically examine whether a long-run relationship exists between the portfolio of stock returns and the Baltic Tanker Index exist, we need to first test for the existence of a cointegrating relationship. In other words, there needs to be an empirical justification for the use of the term in the brackets. However, before we are able to perform the Johansen test for cointegration we first need to establish that both variables are I(1), i.e. they follow a unit root process (for more details see Hendry and Juselius 2000, 2001).

Table 1 presents the results from such an estimation. In particular, we test for the presence of a unit root using both the Augmented Dickey-Fuller test (Dickey and Fuller 1979; MacKinnon 1996) and the Philips and Perron (1988) tests at the levels and the first differences. The main difference between the two tests is that the first uses a parametric approach based on the residuals while the second is nonparametric. The results suggest that there is evidence of a unit root in the case of $\ln P_{t}$, and $\ln B T_{t}$ given that neither test rejects the unit root hypothesis. The fact that the series are I(1) is confirmed in the lower panel of Table 1 as the null of a unit root is rejected in the first differences of the variables. As such, given that both variables follow a unit root process, we can proceed with testing for a cointegrating relationship.

Using the Johansen (1991) method, we test for the presence of a cointegrating relationship in a vector autoregressive setup. The rank of the error-correction matrix $\delta$ is found to be one in both the maximum eigenvalue and the trace tests, hence confirming the existence of one co-integrating relationship (Table 2). Following the Granger representation theorem (Engle and Granger 1987), if two variables are cointegrated, then at least one variable should Granger-cause the other. As such, the use of a VEC model is justified by the data generating processes. The following section presents the results from the estimation.

\section{A Cointegrated trading strategy}

Following the AIC criterion, an optimal lag length of 100 was selected. The cointegrating equation results can be found in Table 3. As the findings suggest, the freight rate index (BT) has a strong positive long-run effect on portfolio performance. ${ }^{5}$ In particular, a $1 \%$

${ }^{4}$ For both the BDI and stock market returns, we calculate the weekly averages using the average value during the week.

${ }^{5}$ It should be remembered that the sign of the coefficient should be reversed in the long-run equation. In addition, the positive Error-Correction term in the $\Delta \ln B T_{t}$ equation is correct given the negative sign in the long-run equation. For more on these points see Hendry and Juselius (2001) and Enders (1995). 
Table 2 Cointegration results

\begin{tabular}{lll}
\hline Null & Max Eigenvalue & Trace Test \\
\hline Rank $=0$ & $16.09^{\mathrm{a}}$ & $16.60^{\mathrm{a}}$ \\
Rank $=1$ & 0.51 & 0.51 \\
\hline
\end{tabular}

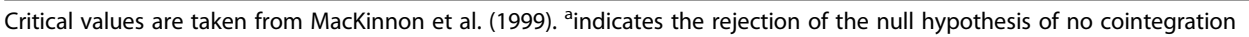
at least at the $5 \%$ level of significance

increase in freight rates would increase the equilibrium (long-run) value of the portfolio by approximately $3.2 \%$. The magnitude of the relationship provides more support to the claim that shipping stock portfolio performance is highly dependent on freight rates. Hence, the use of a trading strategy which employs the relationship between the two appears to be supported by the data.

Figure 1 presents the cointegrating equation. As can be observed, the cointegrating equation follows a pattern around zero (i.e. equilibrium), with notable ups and downs (deviations from the equilibrium), akin to small business cycles throughout the estimation period. Given that the existence of these cycles is more pronounced in the cointegrating relationship than in the actual data, it is thus more convenient for the investor to try to exploit this cyclicality. To this end, we employ two moving averages: a six-week (longrun) moving average of the cointegrating equation, denoted as MA(6), and the lag of the relationship (short-term) denoted as MA(1). A similar setup was employed by Alizadeh and Nomikos (2006).

As in usual technical analysis, we consider crossovers to determine the strategy. In particular, when the short-run moving average exceeds the long-run moving average then this is a buy signal as it suggests that prices are moving higher at a faster rate than in the past. In contrast, when the short-run moving average passes below the long-run moving average we consider this as a sell signal. In-between the crossovers, we simply follow the crossover and the strategy dictates that we continue to be in the market, i.e. after a buy signal the algorithm buys and holds until a sell signal is found. To make the setup more realistic we impose a transaction cost equal to $0.5 \%$.

The results from the trading strategy can be found in Fig. 2. Given that it is known that trading strategies highly depend on the investment horizon (Dierkes et al. 2010), we provide results for four different starting points: the start of the sample, 2009, 2011, and 2013. ${ }^{6}$ The findings suggest that the strategy appears to be more successful at the end of horizon, compared to the simple buy-and-hold strategy. However, the starting point makes an important difference for the overall portfolio performance. Starting our investment strategy in 2009 or 2011 the cointegrating strategy would have simply reduced the potential losses from a buy-andhold strategy. In particular, the buy-and-hold strategy resulted in $86.6 \%$ and $71.6 \%$ losses while the trading strategy resulted in $57.8 \%$ and $44.3 \%$ losses during the period. In contrast, in the 2013 and 2015 starting points the strategy would have resulted in $19.5 \%$ and $26.3 \%$ gains for the cointegrating strategy compared to losses standing at $32.5 \%$ and $55.0 \%$ for buy-and-hold.

As the results suggest, the cointegrating strategy appears to have correctly identified the drop in the value of the portfolio in the summer of 2016 and issued a sell signal. This contributed to large gains, in contrast to the buy-and-hold which faced severe

${ }^{6}$ Changes in the starting points has no qualitative impact on the conclusions reached. 
Table 3 VECM results

\begin{tabular}{lll}
\hline Long-run & & \\
\hline $\mathrm{P}_{\mathrm{t}-1}$ & 1.00 & \\
$\mathrm{BT}_{\mathrm{t}-1}$ & $-3.19^{* * *}(0.65)$ & \\
Constant & 17.42 & $\Delta \ln B T_{\mathrm{t}}$ \\
Short-run & $\Delta \ln \mathrm{P}_{\mathrm{t}}$ & $0.01^{*}(0.00)$ \\
$\mathrm{EC}_{\mathrm{t}-1}$ & $-0.01^{*}(0.01)$ & -3.64 \\
Akaike Criterion & -3.15 & -1.77 \\
\hline Schwarz Criterion & -1.28 & \\
\hline
\end{tabular}

*** and $*$ indicate significance at the $1 \%$, and $10 \%$ levels respectively

losses. Throughout time, there appear to be period during which some strategy outperformed the other. Only in panel (a) does the cointegrating strategy remain above the buy-and-hold in almost all periods and is very close to it in the mid-2015 to mid-2016 period.

An important point to bear in mind is that, while the trading rule appears to be very profitable in some periods, its success could be perhaps enhanced by not simply relying on a mechanical use. Furthermore, Fig. 2 points out that the rule appears to perform better in downturns and hence may be more suitable as a hedging companion to a buy-and-hold strategy. This could perhaps mitigate the buy-and-hold strategy's main drawback, i.e. not having an alternative to downturns. A very simple combination would entail averaging exposure in both strategies, leading to an ability to have more stable returns over time. The use of portfolio optimisation techniques could also perhaps be useful in creating a more efficient allocation. However, given that this is beyond the scope of this paper, we leave this very interesting implication for future research.

\section{Conclusions}

We propose a trading strategy that is derived from the close association between tanker market freight rates and the stock returns of tanker companies. This relationship holds

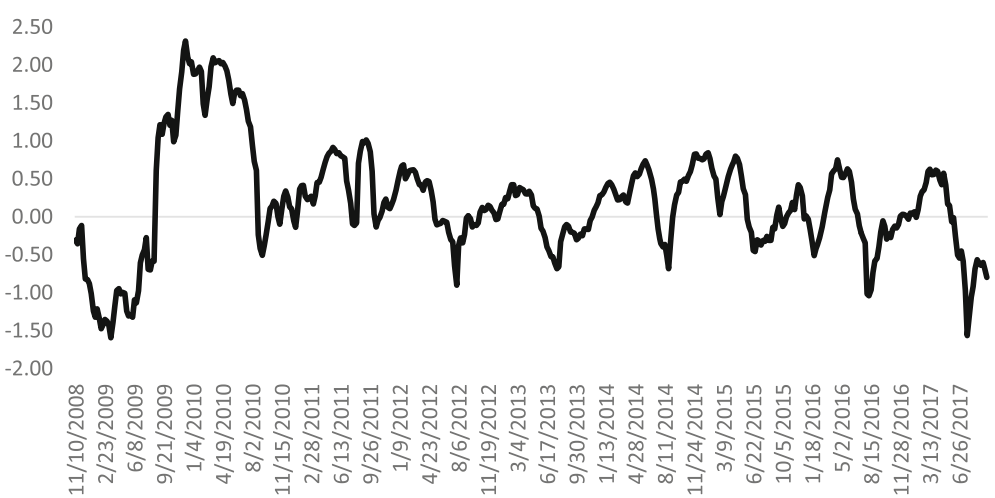

Fig. 1 Cointegrating Equation. The cointegrating equation revolves around zero (equilibrium). Deviations from the equilibrium allow for the use of a trading strategy to exploit the eminent return of the relationship to the equilibrium level 


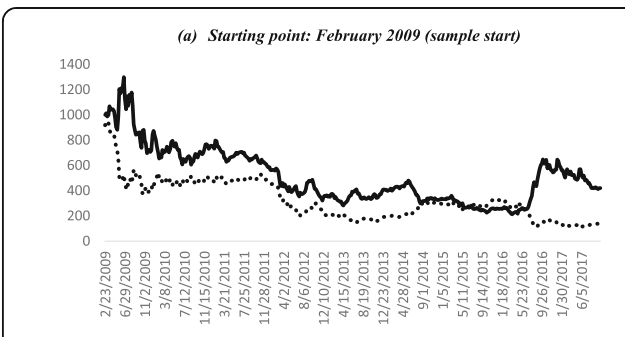

(c) Starting point: January 2013

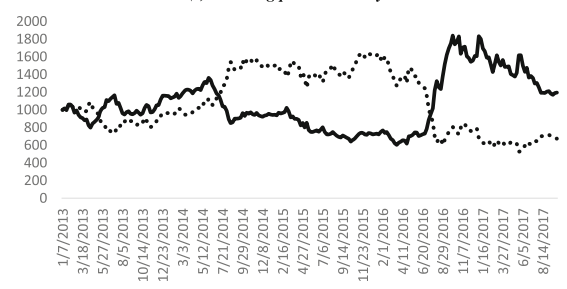

(b) Starting point: January 2011

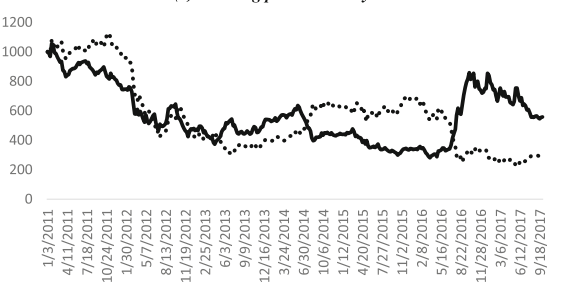

(d) Starting point: January 2015

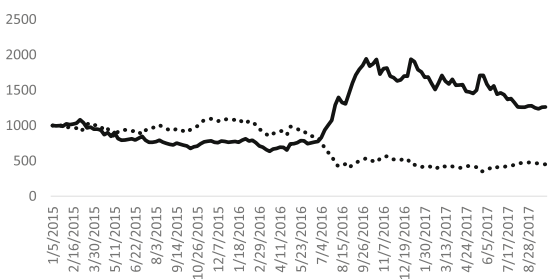

Fig. 2 Returns on the strategies. Figure 2 presents the portfolio returns using the cointegrating strategy (solid line) as opposed to using the buy-and-hold strategy (dashed line) for various starting points. Starting period varies starting from February 2009, January 201, January 2013 and January 2015. Each portfolio starts with the assumptions that 1000 dollars are invested both in the buy-and-hold and the trading strategy portfolio. Thus, in all graphs the lines have a starting point of a 1000 basis points

in the long-run and hence the use of a cointegration approach based on a portfolio of the US-listed tanker companies and the Baltic Tanker Index on a weekly basis, is warranted. Our results show that, while the choice of the investment horizon matter, a strategy using the cointegrating relationship and a simple moving average rule appears to be more successful at the end of horizon, compared to a simple buy-and-hold strategy. Its success in downturns also allows the strategy to be useful as a hedging tool.

\section{Abbreviations}

AIC: Akaike Information Criterion; BDI: Baltic Dry Index; IPO: Initial Public Offering; M\&A: Mergers and Acquisitions; MA: Moving Average; SIC: Standard Industrial Classification; US: United States; VEC: Vector Error Correction

\section{Acknowledgements}

Not applicable.

\section{Authors' contributions}

KD performed the literature review and collected the data required for the econometric estimation. NM performed the estimation, created the methodology, interpreted the results and drafted the conclusions of the study. Both authors read and approved the final manuscript.

\section{Funding}

No funding was provided for this study.

\section{Availability of data and materials}

The datasets generated and/or analysed during the current study are available in the Clarksons' Intelligence Network and Thompson-Reuters Eikon repositories.

\section{Competing interests}

The authors declare that they have no competing interests.

\section{Author details}

${ }^{1}$ Economic Analysis and Research Department, Central Bank of Cyprus, School of Economics and Business, Cyprus University of Technology, and Cyprus Centre for Business Research, 80, Kennedy Avenue, 1076 Nicosia, Cyprus. ${ }^{2}$ School of Business and Management, University of Central Lancashire, Cyprus Campus, 12 - 14 University Avenue Pyla, 7080 Larnaka, Cyprus. 
Received: 27 March 2019 Accepted: 21 September 2019

Published online: 22 October 2019

\section{References}

Alexander C (1999) 'Optimal hedging using Cointegration', Philosophical Transactions: Mathematical. Phys Eng Sci 357(1758): 2039-2058

Alexandrou G, Gounopoulos D, Thomas HM (2014) Mergers and acquisitions in shipping. Transportation Research Part E: Logistics and Transportation Review 61:212-234 https://doi.org/10.1016/j.tre.2013.11.007.

Alizadeh AH, Nomikos NK (2006) Trading strategies in the market for tankers. Marit Policy Manag 33(2):119-140. https://doi. org/10.1080/03088830600612799

Andriosopoulos $\mathrm{K}$ et al (2013) Portfolio optimization and index tracking for the shipping stock and freight markets using evolutionary algorithms. Transport Res Part E Logistics Transport Rev 52:16-34. https://doi.org/10.1016/j.tre. 2012.11.006

Basak, S. and Pavlova, A. (2016) 'A model of Financialization of commodities', The Journal of Finance. Wiley, 71(4):1511-1556. doi: https://doi.org/10.1111/jofi.12408

Creti A, Joëts M, Mignon V (2013) 'On the links between stock and commodity markets' volatility', vol 37. Energy Economics, North-Holland, pp 16-28. https://doi.org/10.1016/J.ENECO.2013.01.005

DeBondt WFM, Thaler RH (1985) Does the stock market overreact? J Financ 40(3):793-805. https://doi.org/10.1111/j.15406261.1985.tb05004.x

Dickey DA, Fuller WA (1979) Distribution of the estimators for autoregressive time series with a unit root. J Am Stat Assoc 74(366):427. https://doi.org/10.2307/2286348

Dierkes M, Erner C, Zeisberger S (2010) Investment horizon and the attractiveness of investment strategies: a behavioral approach. J Banking Finance 34(5):1032-1046. Elsevier B.V. https://doi.org/10.1016/j.jbankfin.2009. 11.003

Drobetz W, Schilling D, Tegtmeier $L$ (2010) Common risk factors in the returns of shipping stocks. Marit Policy Manag 37(2): 93-120. https://doi.org/10.1080/03088830903533726

El-Masry AA, Olugbode M, Pointon J (2010) The exposure of shipping firms' stock returns to financial risks and oil prices: a global perspective. Marit Policy Manag 37(5):453-473. https://doi.org/10.1080/03088839.2010. 503713

Enders W (1995) Applied econometric time series. In: Wiley Series in Probability and Mathematical Statistics

Engle RF, Granger CW (1987) Co-integration and error correction: representation, estimation, and testing. Econometrica 55(2): 251. https://doi.org/10.2307/1913236

Ghosh A (1991) Hedging with stock index futures: estimation and forecasting with error correction model. J Futur Mark 13(7): 743-750. https://doi.org/10.1002/fut.3990130703

Grammenos CT, Arkoulis AG (2002) Macroeconomic factors and international shipping stock returns. Int J Marit Econ 4(1):8199. Palgrave Macmillan UK. https://doi.org/10.1057/palgrave.ijme.9100033

Grammenos CTH, Marcoulis SN (1996) A cross-section analysis of stock returns: the case of shipping firms. Marit Policy Manag 23(1):67-80. https://doi.org/10.1080/03088839600000053

Harlafti G, Papakonstantinou K (2013) The Shipping industry of the Greeks: The century of prosperity before the revollution. Ionian University, Chios, Greece: Kedros Publishing

Harlaftis G, Theotokas G (2007) Greek shipowners and shipping companies - Organization,management and strategy. Allexandria Publishications, Athens

Hendry DF, Juselius K (2000) Explaining Cointegration analysis: part I. Energy J 21(1):1-42 Doi: 01956574

Hendry DF, Juselius K (2001) Explaining Cointegration analysis : part II. Energy J 1:75-120. https://doi.org/10.2307/41322908

Johansen S (1991) Estimation and hypothesis testing of Cointegration vectors in Gaussian vector autoregressive models. Econometrica 59(6):1551-1580

Johansen S, Juselius K (1990) Maximum likelihood estimation and inference on Cointegration - with applications to the demand for money. Oxf Bull Econ Stat 52(2):169-210. https://doi.org/10.1111/j.1468-0084. 1990.mp52002003.x

Kavussanos MG, Marcoulis SN (2000a) The stock market perception of industry risk and macroeconomic factors: the case of the US water and other transportation stocks. Int J Marit Econ 2(3):235-256. Palgrave Macmillan UK. https://doi.org/10.1057/ijme.2000.19

Kavussanos MG, Marcoulis SN (2000b) The stock market perception of industry risk through the utilisation of a general multifactor model. International Journal of Transport Economics:77-98. Rivista internazionale di economia dei trasporti. Accademia Editoriale. https://doi.org/10.2307/42747443

Kroner KF, Sultan J (1993) Time-varying distributions and dynamic hedging with foreign currency futures. J Financ Quant Anal 28(4):535-551

Lambertides N, Louca C (2008) Ownership structure and operating performance: evidence from the European maritime industry. Marit Policy Manag 35(4):395-409

Mackinnon JG (1996) Numerical distribution functions for unit root and cointegration tests. J Appl Econ 11(6):601-618. https://doi.org/10.1002/(SICI)1099-1255(199611)11:6<601:AID-JAE417>3.0.CO;2-T

Merika A et al (2015) The relationship between business cycles and capital structure choice: the case of the international shipping industry. J Econ Asymmetries 12(2):92-99. https://doi.org/10.1016/j.jeca.2015.04.001

Merikas A, Gounopoulos D, Nounis C (2009) Global shipping IPOs performance. Marit Policy Manag 36(6):481-505

Panayides PM, Lambertides N, Savva CS (2011) The relative efficiency of shipping companies. Transport Res Part E Logistics Transport Rev 47(5):681-694. Elsevier Ltd. https://doi.org/10.1016/j.tre.2011.01.001

Papapostolou NC et al (2014) Investor sentiment for real assets: the case of dry bulk shipping market. Rev Financ 18(4):1507-1539

Papapostolou NC et al (2016) Shipping investor sentiment and international stock return predictability. Transport Res Part E Logistics Transport Rev 96:81-94 Pergamon

Philips PCB, Perron P (1988) Testing for a unit root in time series regression. Biometrika Trust 75(2):335-346. https://doi.org/ 10.1093/poq/nf1045 
Sadorsky P (1999) Oil price shocks and stock market activity. Energy Econ 21(5):449-469. North-Holland. https://doi.org/10. 1016/50140-9883(99)00020-1

Shilling AG (1992) Market timing: better than a buy-and-hold strategy. Financ Anal J 48(2):46-50. https://doi.org/10.2469/faj.v48.n2.46 Syriopoulos T, Roumpis E (2009) Asset allocation and value at risk in shipping equity portfolios. Marit Policy Manag 36(1):5778. https://doi.org/10.1080/03088830802652312

Tezuka K, Ishii M, Ishizaka M (2012) Relationship between CAPM- $\beta$ and market changes in the Japanese liner shipping industry. Marit Policy Manag 39(3):345-367. https://doi.org/10.1080/03088839.2011.625987

\section{Publisher's Note}

Springer Nature remains neutral with regard to jurisdictional claims in published maps and institutional affiliations.

Submit your manuscript to a SpringerOpen ${ }^{0}$ journal and benefit from:

- Convenient online submission

- Rigorous peer review

- Open access: articles freely available online

High visibility within the field

- Retaining the copyright to your article

Submit your next manuscript at $\boldsymbol{\nabla}$ springeropen.com 